\title{
LOOKING IN THE OPPOSITE DIRECTION
}

It has become an anthropological truism to say that it is possible to write the 'biography of an object'; to track its life from creation through the different stages of its ownership, its patterns of use and its progress into old age. It is a useful way of thinking about the 'status' of an object and how it manifests itself through time: how the meanings of an object change in its encounters with people. The biography of one group of Japanese objects, known variously in the West as mingei, Japanese folk craft, Japanese folk art or indeed Japanese art, would be spectacularly complex. Imaging the layerings of the narratives, the twists and turns and uncertainties of our putative object's life through its birth in the deep cultural matrix of Japanese craft to the web of artistic, economic, social and religious aspirations that cause it to be made.

When we see these objects, in an exhibition or in a beautiful catalogue, when we are transfixed by their austerity, their sense of abbreviated gesture, their humour, we are looking at something whose life-history is as gripping as any airport novel. We should take time to think about how we come to be in this extraordinary situation of being able to see things and try to work out why there is such a complex trajectory from workshop or kitchen hearth to cabinet. We can look back on a century or more in which certain Japanese objects, made for use rather than contemplation, have become powerful and iconic representations of a panoply of rich concepts. For some they have come to represent 'timelessness', 'authenticity', 'the Kingdom of Beauty', 'direct simplicity and joy in making'. For others they have become examples of an art of abstraction, a balance of forms, visual weight and mass that are the equal of sculpture. And for an impressive list of artists, designers and architects in the West they have provided a profound source of influence.

The phrase 'truth to materials' has become so commonplace that its radicalism has now been lost, the shock there must have been when seeing unglazed pottery for the first time. This idea of the use of truthful materials meant revealing rather than effacing certain properties of the material. It also meant dramatising a connection between the organic form of the sculpted material and the organic development of the material from which it was carved...' as Rosalind Krauss wrote of Henry Moore. This shows itself as a kind of structural clarity - when you see something you apprehend the manner of its construction. An aesthetic fashioned out of necessity.

Then there is what might be described as the valorising of age. They supply the temporal dimension, the hand patina that tells of use. In the Western 'biography of an object', age usually implies a falling off from the moment of

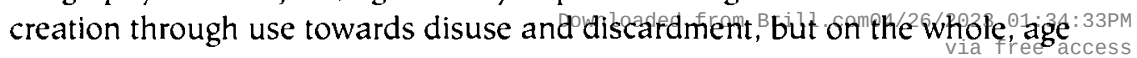




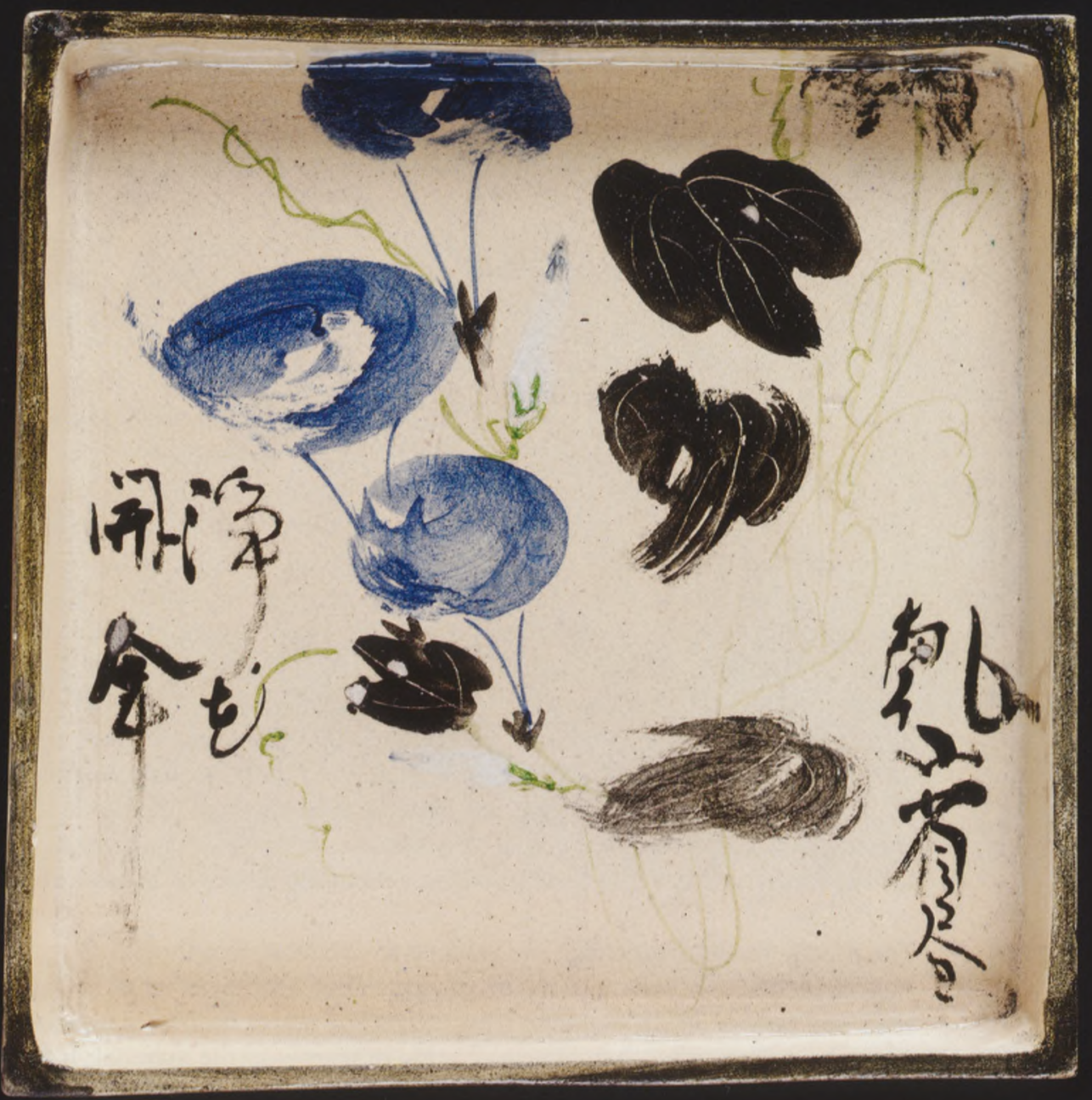


Fig. 2

Square dish (cake dish), buff earthenware with crackled glaze, painted in colours with morning-glory design, I. 20.9 cm., br. 20.9 cm., inscription and signature of $O_{g}$ ata Kenzan (1663-1743); Japan, Sano, 18th century or later, (c) Victoria and Albert Museum, London, number FE.61-1977. was unaesthetic in the coterie of the high arts. So there is an element of the iconoclastic in these Japanese objects here too - they challenge the Western concept that the very integrity of an object is contingent on it remaining unchanged.

\section{Gesture and abstraction}

A key area of influence lies in the power of gestural markings, the sudden explosion of movement such as can be seen in the glaze splashes from the rim of a water jar, mizugame. The implication of a kind of inclusiveness of happenstance was a profoundly unusual way of thinking about the experience of making art. The sense that objects could be made in this way connected to the growth of interest in Zen in the West.

Perhaps the most significant debt - and the most difficult to analyse - to these Japanese arts lies in abstraction. By this I do not mean the lack of images. Many objects have complex iconographies. By abstraction I mean the sense that there is a simultaneous apprehension of form as the meeting place of utilitarian requirement and decorative impulse, and a sculptural compulsion.

In each case the language in which these Japanese objects have been described is weighty and to some extent codified. How this happened through the agency of particular charismatic artists, collectors and critics, most notably Christopher Dresser, Edward Morse, Soetsu Yangai and Bernard Leach, is a piece of fascinating cultural history. The language of description that has shaped the aesthetics of Western views of these Japanese things is their language of prescription. This has also made certain characteristics acceptable and others beyond the pale: some objects fitted their patterning of 'good' Japanese taste and some most certainly did not. They have provided a lens through which much has been refracted, their vocabularies - and hence their conceptual frameworks - have been used wholesale and with usualness that has occluded the dense specificity of meanings that these objects have had in Japan.

\section{Wonder}

As it is only in the last twenty years that there have been attempts to critique the assumptions of these writers, it will be an uphill struggle to change the ways in which these arts are talked about. The romantic projection onto Japan as a place of happy, intuitive craftspeople still runs deep. We need to reach out to the balance that the theorist Stephen Greenblatt talked of as the pull between 'resonance' and 'wonder' that happens in our encounter with art in an exhibition.

In analysing the effects on the West of what I shall call the Japanese arts, far too often there has been the swooning, the 'wonder' aspect. In the first encounters in the West with these new kinds of objects, there was just this mixture of beguilement and shock, best seen in the reactions to the new pots of Japan shown at the Paris Exposition in 1878. These were the tea wares; pots that had emerged from the vernacular and rural traditions, and had been chosen by tea masters as expressions of vigour and freedom. Often warped or slumped, and mainly monochromatic, the emphasis here was on geserure ie : 34: 33рм 
either in the flow of glaze or in the marks of throwing. It was obvious that these new kinds of pots required a particular aesthetic.

A late Victorian commentator acknowledged that 'a connoisseur must have been specifically educated when he consents to pay ten or twenty guineas for a water holder that might be easily mistaken for a drainpipe, partially blackened by fire and ornamented by patches and streaks of brick colour'. That there were such connoisseurs around, albeit few in number, can be seen in the critical reception accorded to these pots when exhibited at the grand international expositions; bafflement giving way to a grudging respect for what was described in 1901 as 'a world in which pottery was not ashamed of its earthy origin or the human fingers that fashioned it, but was content in the satisfactory fulfilment of its mission'.

\section{Process}

The very idea of the fulfilling of a mission implies a radically different way of thinking about how clay is used, of clay as possessing an essential character that needed to be respected. This was a focus on the process of making and firing - in contradistinction to the ideal of Chinese porcelains where the processes of making were subsumed into the idealised object. Here the pot could be said to be a celebration of process rather than its transcendence. And this was a point that Christopher Dresser had made in his report on Japanese pottery in 1871: 'I have before me some specimens of Japanese earthenware, which are formed of a coarse dark-brown clay, and are to a great extent without the finish which most Europeans appear so much to value, yet these are artistic and beautiful. In the case of cheap goods we spend time in getting smoothness of surface, while the Japanese devote it to the production of art effect. We get finish without art, they prefer art without finish'.

The challenge that these objects offered was thus two-fold. One was aesthetic. Japanese pottery seemed to break away from any known canon: 'some modern specimens of Japanese pottery are curiously and intentionally deformed - crooked, twisted, or bulging like a sack of potatoes - and, nevertheless, in the most refined taste...' The second was conceptual, the very idea that 'refinement' or 'art effect' could be predicated on distortion or coarseness was new. And if one wants to try and track the ways in which these quotidian objects have become influential in the West, it is useful to examine the language of the artists, critics and curators who have mapped these Japanese arts. Perhaps the most compelling description comes in Bernard Leach's version of Soetsu Yangai's essay on the Kizaemon teabowl. The essay focuses on the Korean maker of the bowl, stressing that the primary marker for authenticity is that the maker of the object must not be self-aware, must be unconscious of the possibility of unauthencity in making. Therefore the process of making must be consuming, even self-abnegating, allowing little of the destructive self-consciousness that has infected the West.

It is a piece of what might be described as an aesthetic ethnography, a way of making attractively comprehensible the conditions in which the bowl was made, a bowl that a poor man would use every day... a typical thing for his 34 : 33рм 

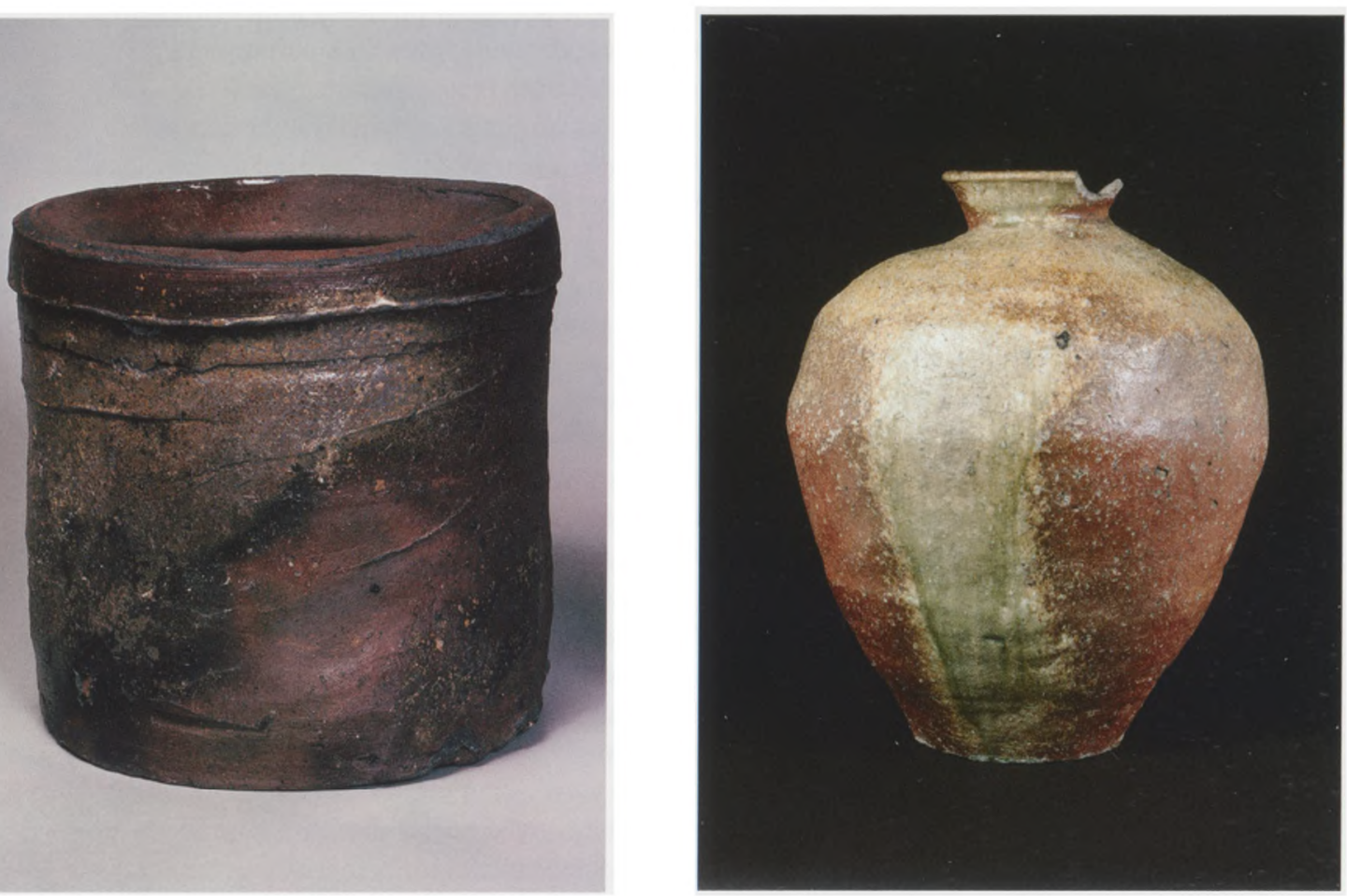

Fig. 3 (left)

Fresh-water jar, stoneware with natural ash glaze, h. $16.5 \mathrm{~cm}$., d. $17.8 \mathrm{~cm}$., Japan, Bizen, 1600-1700, (C) Victoria and Albert Museum, London, number 188-1877.

Fig. 4

Jar, stoneware with natural ash glaze,

h. $49.5 \mathrm{~cm}$., Japan, Shigaraki kilns, 1400 1450, (c) Victoria and Albert Museum, London, number FE.20-1984. use; costing next to nothing; made by a poor man; an article without the flavour of personality; used carelessly by its owner; bought without pride; something anyone could have bought anywhere and everywhere. That is the nature of this bowl. The clay has been dug from the hill at the back of the house; the glaze was made with the ash from the hearth; the potter's wheel had been irregular. The shape revealed no particular thought: it was one of many. The work had been fast; the turning was rough, done with dirty hands; the throwing slipshod; the glaze had run over the foot. The throwing room had been dark. The thrower could not read. The kiln was a wretched affair; the firing careless. Sand had stuck to the pot but no one minded; no one invested the thing with any dreams. It is enough to make one give up working as a potter... The plain and unagitated, the uncalculated, the harmless, the straightforward, the natural, the innocent, the humble, the modest: where does beauty lie if not in these qualities? Only a commonplace practicality can guarantee health in something made'. Thus Yangai's Korean potter, healthily illiterate, naturally aesthetic, too busy to be self-conscious, became the iconic figure of the Oriental craftsman.

\section{East West}

The shaping of western understanding of Japanese crafts has also been the product of the actual encounters of Japanese craftsmen and artists. The most

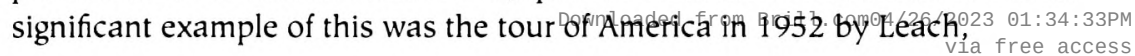


Hamada and Yanagi. Leach lectured on his pottery workshop at St Ives and Yanagi on aesthetics, but it was the vigour with which Hamada threw and decorated that provided the most memorable outcome from the visit. His relaxedness in brushing slip onto a pot, or in trimming a foot-ring found an audience receptive to new and responsive approaches of handling clay. For a post-war generation of American potters and students watching Japanese potters use the wheel, not as an exercise in making perfect forms but as a starting-point for other kinds of manipulation, seemed to show how academicised American thrown pottery had become.

The tension between the expected and planned, the centrifugal force of the pot on wheel and the spontaneous gesture that disrupts this, is central to many Japanese ceramic traditions. Iga and Shigaraki pots with their gaping rents from the firing, or Bizen pots with their dented sides from gestural handling were known through photographs. It was exciting partly because the potters were so relaxed. Hamada at Black Mountain College in 1952 said he could 'make do' with the materials to hand. This was pottery, and crucially the making of vessels, as an exploratory, improvisational art.

That it was an art - the conscious selection of a medium and its expression was most apparent in the visit of Rosanjin Kitaoji. Rosanjin, the famously cussed potter, gourmand and restauranteur whose studio in Tokyo bore the sign 'Beautiful Useful Cultural: Rosanjin Greatest Artist in Japan', spectacularly failed to fit into Yanagi's normative view of the proper (humble) conduct of a Japanese artist, who might be described as the mingei narrative. The consolatory spiritualising of the craftsman could not withstand the actual encounters: it all became much more complex when you met the people who did it.

But these potters also made a bridge with the burgeoning excitement in Zen. For America in the 1950s Zen came mediated through the writings of DT Suzuki and Alan Watts: they showed a world where spontaneity and sudden violent expression were markers of real communication, where conventions were waiting to be broken asunder at revelatory moments. It meant iconoclasm - 'looking in the opposite direction' as Suzuki put it. Zen became a shorthand way of describing a particular expressionist approach to making art.

It is just this 'looking in the opposite direction' that continues to underlie the multiplicity of interpretations of these Japanese arts in the West. Their capacity to move us to 'wonder' remains undiminished, the challenge of their 'resonance' is still with us. 